\title{
Effect of Lycra percentage on the physical properties of single jersey weft knitted fabric
}

\begin{abstract}
This research studies the effect of increase percentage of Lycra yarns during loop formation on the geometrical, physical mechanical properties of plain jersey fabrics. Samples with $100 \%$ cotton yarns, Lycra yarns in alternating courses (half feeder) and Lycra yarn in every courses (full feeder) were produced on a circular knitting machine, the two later cases were produced at five different levels of Lycra extension. Thermal setting was carried out without any traverse tension during finishing thus evaluates the full effect of Lycra extension. Results show a sharp increase in the course density rather than the wales density. Fabric thickness and weight per unit area also increased and air permeability in the case of the half and full plating fabrics decreased considerably. The breaking load and extension also increased while the initial electricity modulus decreased with an increase in abrasion resistance in the case of full plating. A comparison between half and full feeder methods contribute improving fabric quality by determining optimal Lycra percentage.
\end{abstract}

Volume 6 Issue I - 2020

Asit Ghosh,Asif Ahmed Tonmoy, Saurov Saha

Department of Textile Engineering, Faculty of Engineering,

Daffodil International University, Bangladesh

Correspondence: Asit Ghosh, Assistant Professor, Department of Textile Engineering, Faculty of Engineering, Daffodil International University, Bangladesh, Tel 0I74I886680, Email sit@daffodilvarsity.edu.bd

Received: February 04, 2020 | Published: February 19, 2020

Keywords: Lycra, half feeder, full feeder and knitting

\section{Introduction}

\section{Purpose and significant of study}

A physical property describes a state of a physical system are often referred to as observables. The effect of Lycra fiber on the physical properties of single jersey knitted fabric such as strength, elasticity, shrinkage, spirality etc. ${ }^{1}$

\section{Aim of project}

This project intends to identify physical property (diameter, GSM, shrinkage, spirality etc.) of the full feeder and half feeder Lycra weft knitted single jersey fabric.

\section{Objectives:}

A. To know about the effect of Lycra on the physical properties of single jersey fabric.

B. To know the advantage of adding Lycra in single jersey fabric.

\section{Research question}

How does Lycra\% effect on the physical properties of single jersey fabric?

\section{Review}

A physical property is measureable whose value describes a state of a physical form. Physical properties are often referred to as observables. The effect of Lycra fiber on the physical properties of single jersey knitted fabric such as strength, elasticity, shrinkage, spirality etc.

\section{Lycra}

Lycra is a synthetic elastene fiber that can stretch up to six times its length and returns to its original state again. It was invented in
1958 by Chemist Joseph Shivers at Duponts Benger Laboratory in Waynesboro Virginia.

Generally $(150+40),(150+70),(200+40),(10+70),(16+70)$ Denier yarn is used.

INISTA makes Lycra fiber. It's the supportive company of KOCH INDUSTRIES INC. There are also COOLEX, CORDURA and ANTRON Lycra product used.

Spandex or Lycra is used our textile industry to make up elastene types garments especially in weaving \& knitting garments. Lycra is a Synthetic fiber (man-made fiber) that is used a wide range of skin tight garments, zentia suits, competitive wear, detective sector, shorts, ski pants, yoga pants etc.

\section{Single jersey}

Weft knitting is a knitted piece of fabric where the stitches run from left to right horizontally across the fabric. Types of weft knitting include Jersey (Single, Double), Doubir knit, Circular Knit, Cable knit.

Weft knitted fabrics shrinks easily, good insulator, very elastene, comfortable. Generally used to make up underwear, T-shirts, baby clothes, pyjamas knitwear such as jumpers, scarves, hats and gloves etc.

Single Jersey fabric is weft knitted fabric which formed by one set of needles. In single jersey the appreance of face side and back side is different. This fabric is much warns flexible, stretchy and wears to comfort.

Full feeder: Elastene or Lycra used in the every feeder with yarn is called full feeder.

Half feeder: Elastene or Lycra used in the alternative feeder with yarn is called half feeder. 


\section{Why single jersey is used?}

Mainly elastene yarn is used in single jersey to increase the elastic property. And shrinkage, spirality, gsm(gram per square meter) etc variation are noticed on single jersey.

\section{Historical background}

Byezit $^{2}$ investigated the dimensional and physical properties of full feeder cotton spandex single jersey fabrics and compared the results with half feeder cotton spandex single jersey knitted fabrics. It was apparent that as the amount of spandex increased the loop length value remained nearly the same and the course and wale spacing decreased. Furthermore, because spandex containing fabrics tend to be tighten. The weight per unit area and thickness of the fabrics are higher but the permeability, the pilling grade, and the spirality are on lower side.

Herath $^{3}$ studied the dimensional characteristics of a core spun cotton/spandex interlock structure. The results were compared with those for similar fabrics knitted from $100 \%$ cotton. Diamentional characteristics for both types of samples were measured by considering the change of the courses and the wale and the stitch densities under dry, wet and full relaxtion conditions. It was found that, the wale and the course densities were lower for $100 \%$ cotton structure during relaxtion. Also, the stitch density variations of cotton/ spandex interlock structures were significantly higher than the ones of $100 \%$ cotton during relaxation.

Chathura $^{4}$ studied the dimensional stability of core spun cotton/ spandex single jersey structure with high, medium and low tightness factors under dry, wet and full relaxtion conditions. Results were compared with those for similar fabrics knitted from $100 \%$ cotton fabrics. The courses, the wales and the stitch density were increased with of the relaxation and higher values were reported with cotton/ spandex 1x1 rib knitted structures.

Serkan Tezel $^{5}$ investigated the effect of spandex brand, the tightness factor of the base and spandex yarn on the dimensional and physical properties of cotton/spandex single jersey fabrics. This was done in order to produce tight, medium and loose. Four different spandex yarns were used. Shown that the largest tension values under a constant draw ratio give the highest the weight per unit area, the number of courses $/ \mathrm{cm}$, the number of stitches $/ \mathrm{cm}^{2}$, the thickness but lowest the air permeability values.

Most of the researches ${ }^{2-8}$ studied the diamentional and physical properties of the knitted fabric produced from core spun yarn and few of these researches investigated the properties of the knitted fabric

Table 2 Machine details of Single Jersey produce from cotton and Lycra yarns. As Lycra yarns are often used in alternating courses (half plating) instead of every the course (full plating) either for economical reasons or for better fabric quality, there is a necessity to compare these two cases under different levels of the lycra extension percent. Such comparison is the aim of this research.

\section{Method}

In this experiment we used manual method, ISO, \& AATCC methods on four properties of fabric (Dia, Fabric weight, Shrinkage \& Spirality).

Diameter is considered as the width of fabric. In this experiment we measure the fabric diameter by manual process with the help of measuring tape.

The outcome of how a fabric has been woven or knitted is known as Fabric weight. Fabric weight is measured by electric balance, after cutting with GSM cutter (ISO 33071 method is used).

The process in which a dimension of fabric reduces or increases and fabric becomes smaller or longer than its original size (either widthwise, lengthwise or both) is called as shrinkage of fabric. Shrinkage is determined with $\mathrm{m} / \mathrm{c}$ washcator (ISO 6330 method is used).

Spirality is the de-twisting tendency of yarn in the fabric. Spirality is measured with method AATCC 179 (Table 1).

Table I Testing methods and equipments

\begin{tabular}{lll}
\hline Tests & Methods & Equipments \\
\hline Dia & Manually & Measuring Tape \\
Fabric Weight & ISO 3307I & GSM Cutter, \\
& & Electric Balance \\
Shrinkage & ISO 6330 & Washcator \\
Spirality & AATCC I79 & N/A \\
\hline
\end{tabular}

\section{Material used:}

a. Single jersey fabric

b. Circular knitting machine

c. GSM cutter

d. Lycra

Machine details: Single Jersey (Table 2)

\begin{tabular}{llllll}
\hline $\mathbf{m} / \mathbf{c}$ details & Origin & $\mathbf{m} / \mathbf{c}$ model & $\mathbf{m} / \mathbf{c}$ dia & $\mathbf{m} / \mathbf{c}$ guage & No of feeder \\
\hline Keum-Young & KOREA & KM-3WVX & 30 & $24 / 32$ & 90 \\
\hline
\end{tabular}

\section{Knitting parameters:}
i. Fabric Type: Lycra Single Jersey
ii. Width: 64" open end
iii. Fabric Color: 63/Olive

\author{
iv. Yarn Brand: Sports master \\ v. Yarn details: 40/1+ 20D Lycra-Cb-S.king-435-2.70mm \\ Washing stage: Washing $\mathrm{m} / \mathrm{c}$ details (Table 3 )
}


Table 3 Washing machine details

\begin{tabular}{llllll}
\hline M/c Brand & Origin & Model & Efficiency & Maximum capacity & Compressed air $\left(\mathbf{N m} \mathbf{N}^{3} / \mathbf{k g}\right)$ \\
\hline Tonello & Italy & 70LD & $88 \%$ & $200 \mathrm{~L}$ & 0.005
\end{tabular}

Condition: Water-40L (cold)->5minutes run

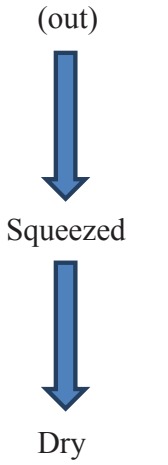

Heatset stage: M/c Brand: Stenter m/c

M/c Brand: Bruckner (Table 4)

Table 4 Heatset stage

\begin{tabular}{lllll}
\hline M/c rpm & Temperature $\left.^{\circ} \mathrm{C}\right)$ & Over fit & Allow dia & Time \\
\hline 19 & 200 & $40 \%$ & 61 & 30 minutes \\
\hline
\end{tabular}

\section{Condition}

Bleaching stage:

A. M/c Brand: ERBATECH Bleaching Machine.

B. Origin: Germany.

\section{Condition}

Temperature $95^{\circ} \mathrm{C}+25 \mathrm{~g} / \mathrm{L} \mathrm{H}_{2} \mathrm{O}_{2}+22 \mathrm{~g} / \mathrm{L}$ costic soda $+4 \mathrm{~g} / \mathrm{L}$ stabilizer $+1 \mathrm{~g} / \mathrm{L}$ Sequestering agent $+\mathrm{pH} 5$ +average $400 \mathrm{~L}$ water + then drying at $140-170^{\circ} \mathrm{C}$

\section{Dyeing stage:}

Exhaust dyeing

M/c Brand: DILMENLER

Origin: Turkey

\section{Condition:}

Dyeing Bath: enzyme 0.3\%

Fabric: Water $=3: 7$

Dimensional Stability: Sample cutting $(50 \mathrm{~cm} \times 50 \mathrm{~cm})$ \& sewing 4 side

After 4 hours condition

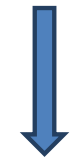

According to ISO 139 temp: $(20+-2){ }^{\circ} \mathrm{C}, \mathrm{RH}=65+-4 \%$
Marking $(35 \mathrm{~cm} \times 35 \mathrm{~cm})$

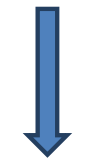

$2 \mathrm{~kg}$ Balest combined with sample

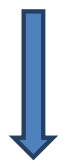

ISO $5 \mathrm{~A}-40^{\circ} \mathrm{C}$, Dry, after 4 hours condition

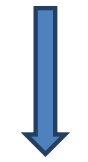

According to ISO 139 temp: $(20+-2)^{\circ} \mathrm{C}, \mathrm{RH}=65+-4 \%$

Determination of dimensional change and calculation before wash-after wash.

\section{Measuring}

Shrinkage: After conditioning shrinkage of resin treated sample were measured by using Shrinkage test board and ruler. The raw fabric sample was measured $(35 \mathrm{~cm} \times 35 \mathrm{~cm})$

Shrinkage formula $=\frac{(\text { length before } \text { wash }- \text { length after wash }) \times 100 \%}{\text { length before } \text { wash }}$

Spirality: The length of two diagonals of each sample fabric was measured and spirality was measured from the following formula

$$
\text { Spirality formula }=\frac{2 \times \text { Difference of two diagonals } \times 100 \%}{\text { Addition of the two diagonals }}
$$

GSM: GSM of each samples were measured by GSM cutter.

\section{Results and discussion process}

The chapter provides the details discussion on the factor about effect of Lycra\% on the physical properties of the single jersey fabrics. Different chart and tables are shown to describe the results of various tests. 
Open width of full feeder\& half feederlycra single jersey fabric at different processing stage

Discussions: For full feeder the final width (after final wash) is quite same to initial width but in case of half feeder the width decreases more than full feeder (Table 5) (Figure 1).

Table 5 Different width of single jersey fabric at different process stage

\begin{tabular}{lll}
\hline \multirow{2}{*}{ Processing stage } & \multicolumn{2}{l}{ Open width (Inch) } \\
\cline { 2 - 3 } & Full feeder & Half feeder \\
\hline Grey Fabric & 64 & 64 \\
After Washing & 55 & 60 \\
After Heatset & 69 & 68 \\
After Bleaching & 64 & 62.5 \\
After Dyeing & 62.5 & 60 \\
After final Wash & 63.5 & 58 \\
\hline
\end{tabular}

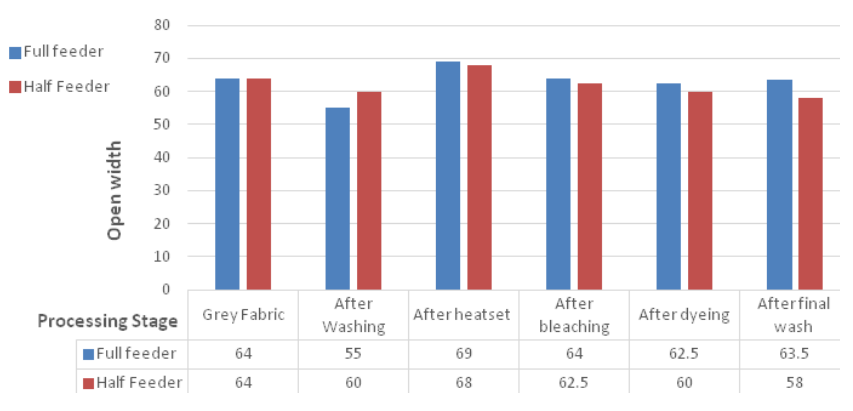

Figure I Open width of full feeder\& half feederlycra single jersey fabric at different processing stage.

\section{GSM of full feeder\& half feederlycra single jersey fabric} at different processing stage

Discussions: For full feeder the fabric weight (after final wash) decreases from initial GSM but in case of half feeder GSM increases (Table 6) (Figure 2).

Table 6 GSM effect on full feeder\& half feederlycra SJ fabric at different stage

\begin{tabular}{lll}
\hline \multirow{2}{*}{ Processing stage } & \multicolumn{2}{l}{$\mathbf{G S M}\left(\mathrm{gm} / \mathbf{m}^{2}\right)$} \\
\cline { 2 - 3 } & Full feeder & Half feeder \\
\hline Grey Fabric & 170 & 120 \\
After Washing & 288 & 191 \\
After Heatset & 155 & 122 \\
After bleaching & 146 & 120 \\
After dyeing & 185 & 138 \\
After Final Wash & 158 & 140 \\
\hline
\end{tabular}

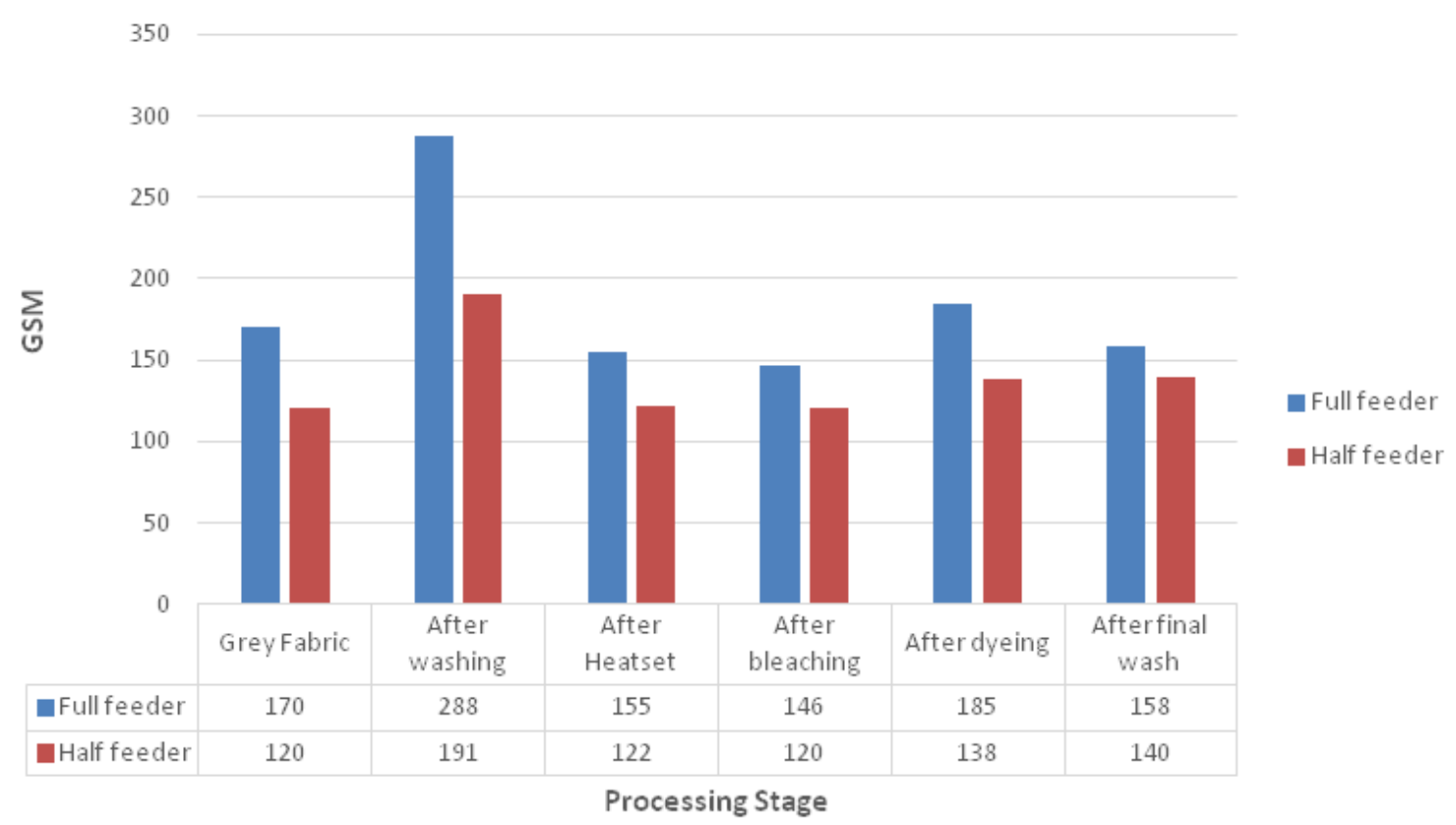

Figure 2 GSM of full feeder\& half feederlycra single jersey fabric at different processing stage. 


\section{Length wise shrinkage of full feeder\& half feederlycra single jersey fabric at different processing stage}

Discussions: For full feeder the final shrinkage \% (after final wash) decreases less than half feeder from initial shrinkage $\%$ in length (Table 7) (Figure 3).
Width wise shrinkage of full feeder\& half feederlycra single jersey fabric at different processing stage

Discussions: Width wise and for half feeder the final shrinkage \% (after final wash) decreases more than full feeder from initial shrinkage $\%$ in length and width wise (Table 8) (Figure 4).

Table 7 Length wise shrinkage of full feeder and half feeder Lycra single jersey fabric at different processing stage

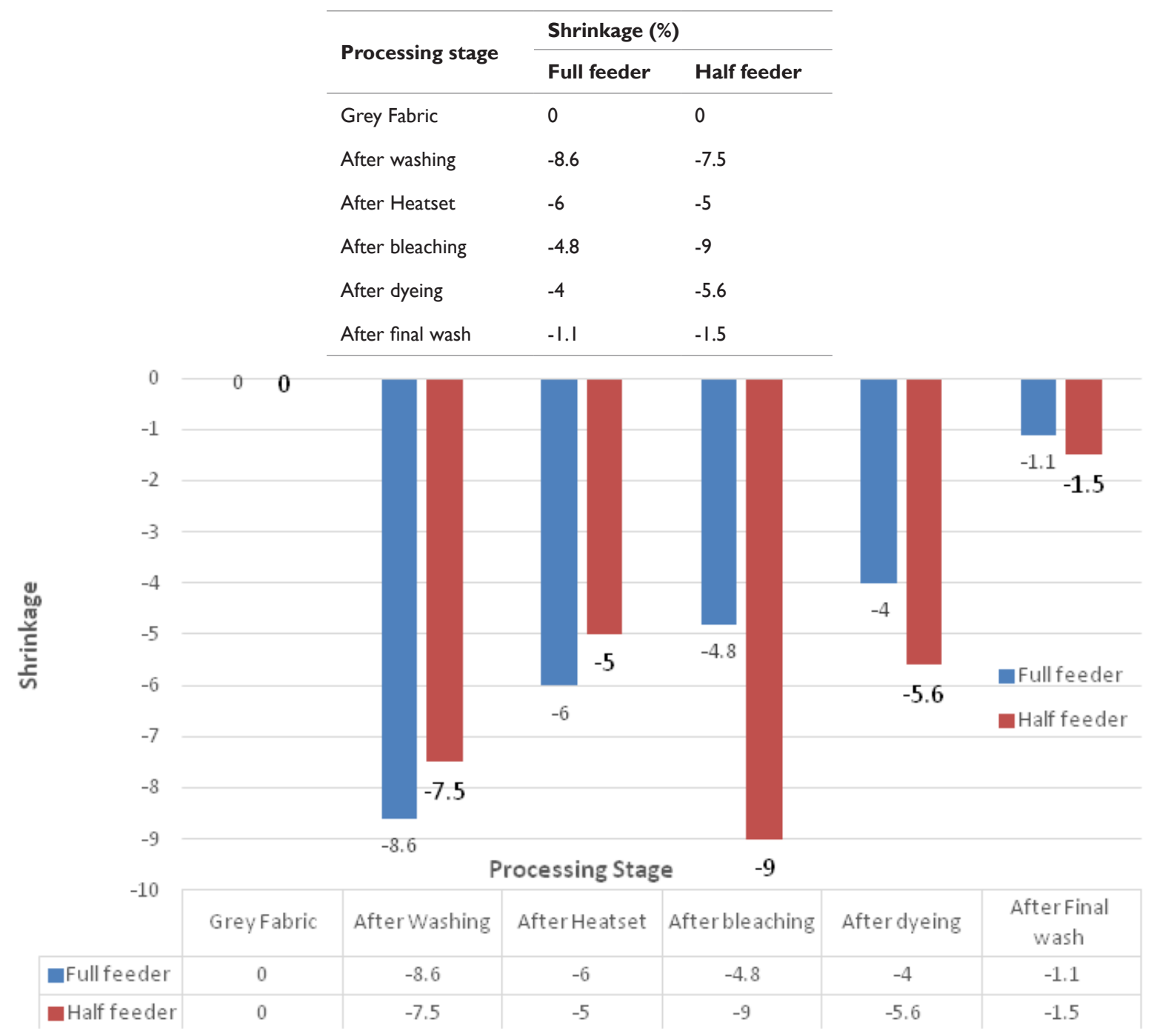

Figure 3 Length wise shrinkage of full feeder\& half feederlycra single jersey fabric at different processing stage.

Table 8 Width wise shrinkage of full feeder and half feeder Lycra single jersey fabric at different processing stage

\begin{tabular}{lll}
\hline \multirow{2}{*}{ Processing stage } & \multicolumn{2}{l}{ Shrinkage (\%) } \\
\cline { 2 - 3 } & Full feeder & Half feeder \\
\hline Grey fabric & 0 & 0 \\
After washing & -5 & -4 \\
After Heatset & -9 & -8 \\
After bleaching & -2.5 & -1.2 \\
After dyeing & -2.6 & -2 \\
After final wash & -0.8 & -0.5 \\
\hline
\end{tabular}




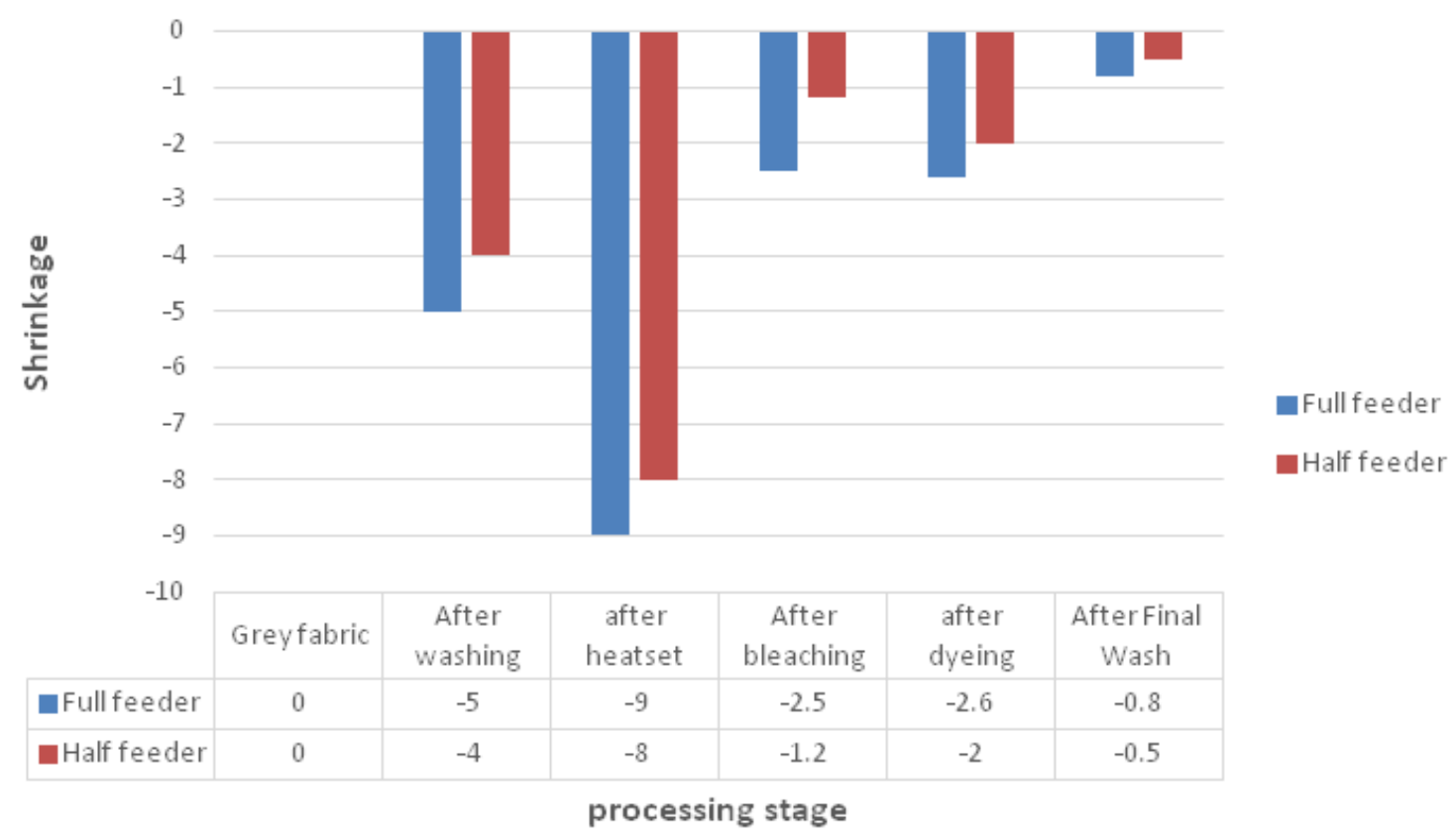

Figure 4 Width wise shrinkage of full feeder\& half feederlycra single jersey fabric at different processing stage.

Spirality of full feeder\& half feederlycra single jersey fabric at different processing stage

Discussions: For full feeder the final spirality \% (after final wash) increases more than half feeder and for half feeder the final spirality $\%$ (after final wash) increases less than full feeder (Table 9) (Figure 5).

\section{Summary}

Lycra has a great effect on single jersey fabric properties which increases the elastic properties on single jersey fabrics.

a) For full feeder the final width (after final wash) is quite same to initial width but in case of half feeder the width decreases more than full feeder. b) For full feeder the fabric weight (after final wash) decreases from initial GSM but in case of half feeder GSM increases.

c) For full feeder the final shrinkage $\%$ (after final wash) decreases less than half feeder from initial shrinkage $\%$ in length\& width wise and for half feeder the final shrinkage \% (after final wash) decreases more than full feeder from initial shrinkage $\%$ in length \& width wise.

d) For full feeder the final spirality \% (after final wash) increases more than half feeder and Forhalffeeder the final spirality \% (after final wash) increases less than full feeder.

Table 9 Spirality of full feeder and half feeder Lycra single sersey fabric at different processing stage

\begin{tabular}{lll}
\hline \multirow{2}{*}{ Processing stage } & \multicolumn{2}{c}{ Spirality (\%) } \\
\cline { 2 - 3 } & Full feeder & Half feeder \\
\hline Grey fabric & 0 & 0 \\
After washing & 2 & 2.5 \\
After heatset & 8 & 8 \\
After bleaching & 10 & 10.5 \\
After dyeing & 2.7 & 2 \\
After final wash & 2 & 1.5 \\
\hline
\end{tabular}




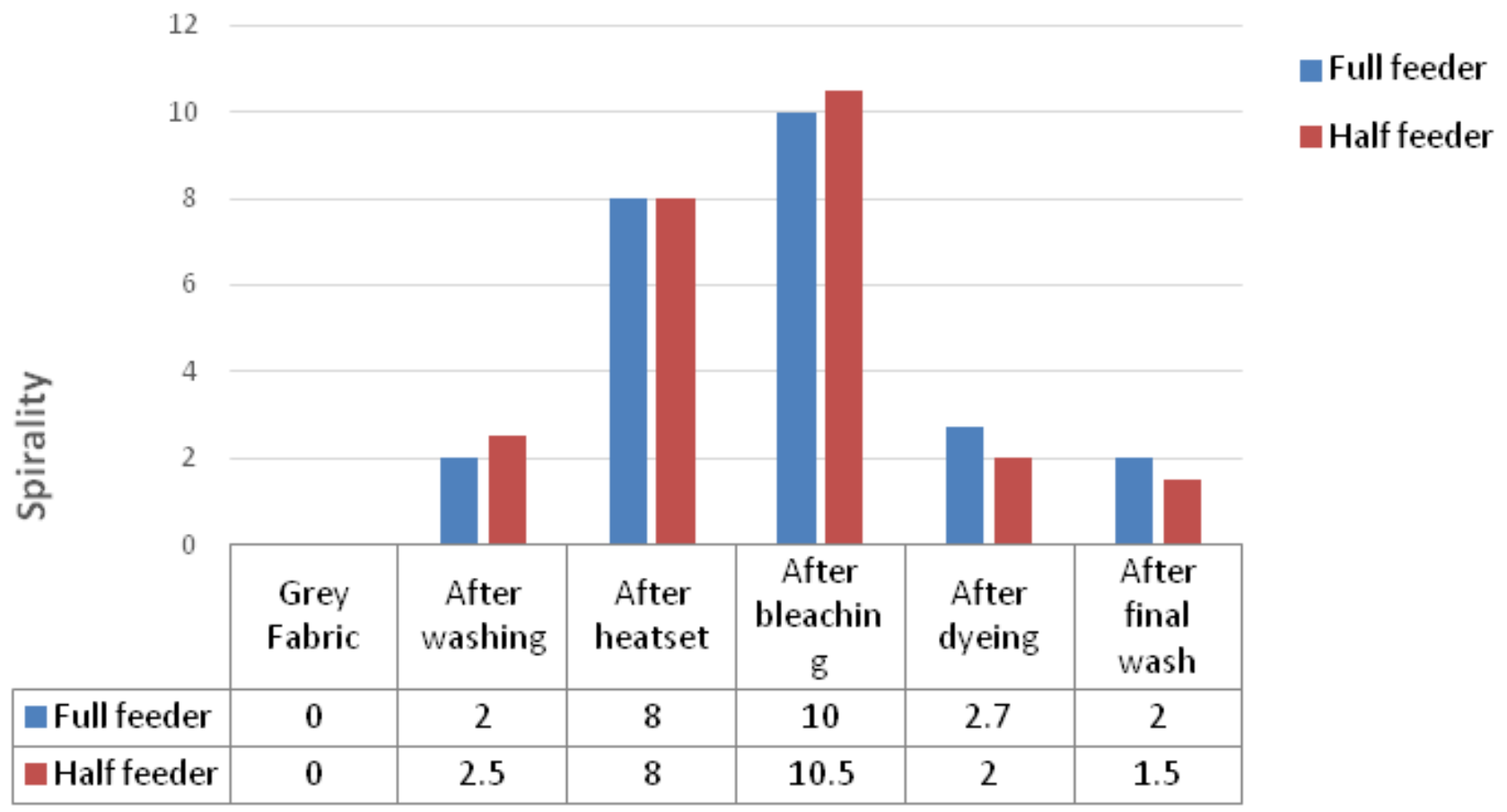

Figure 5 Spirality of full feeder\& half feederlycra single jersey fabric at different processing stage.

\section{Conclusion}

The aim of this project was to know the different properties variation between half feeder and full feeder Lycra single jersey fabric. The available sample was analyzed. We discuss the dimensional and physical properties of full feeder \& half feeder Lycra single jersey fabrics and we conclude that these parameters are affected by the amount of elastane in the fabric. It is also apparent that the widthwise dimensional variations for fabric knitted with half feeder are higher than full feeder while the length wise variations for the same fabrics are less after relaxations at different processing stage.

\section{Acknowledgments}

None.

\section{Funding}

None.

\section{Conflicts of interest}

Authors have declared no conflicts of interest.

\section{References}

1. Haji MMA. Physical and mechanical properties of cotton/spandex fabrics. Pakistan Textile Journal. 2013;62(1):52-55.
2. Marmarali AB. Dimensional and physical properties of cotton/spandex single jersey fabrics. Textile Research Journal. 2003;73)(1):11-14.

3. Kumar V, Sampath VR. Investigations on the physical and dimensional properties of single jersey fabric made from cotton sheath -elastomeric core apun. Fibers \& textiles in Eastern Europe. 2013;99(3):73-75.

4. Senthil kumar M. Elastic knitted fabrics for tight fit sportswear. Journal of Industrial Textiles. 2011;41(1):13-24.

5. Prakash C, Thangamani K. Establishing the effect of loop length on dimensional estability of single jersey knitted fabric made from cotton/lycra core spun yarn," Indian Journal of science technology. 2010;3(3):287-289.

6. Sadek R, El-Hossini AM, Eldeeb AS, et al. Effect of Lycra extension percent on single jersey knitted fabric properties. Journal of Engineeed Fibers and Fabrics. 2012;7(2):11-16.

7. Zaman M. The effect of feeding speeds of elastomeric yarn on dimensional properties of single jersey knit fabric. Faculty of textile Engineering Department, Dhaka, Bangladesh: International University; 2013.

8. Cibi Visnu C, Padmaraj L, Sukanya H, et al. Effect of heat setting and compacting on elastic properties of cotton/spandex knitted fabrics. Department of Textile and Apparel Technology, Coimbatore, India: PSG Polytechnic College; 2015. 